\title{
Phenylacetaldehyde: A chemical attractant for common green lacewings (Chrysoperla carnea s.l., Neuroptera: Chrysopidae)
}

\author{
Miklós TÓTH ${ }^{1}$, AndrÁs BOZSIK $^{2}$, FERENC SZENTKIRÁl YI $^{1}$, AgOSTINo LETARDI $^{3}$, Maria RosARIA TABILIO ${ }^{4}$, \\ MARCello VERDINELLI ${ }^{5}$, Pietro ZANDIGIACOMO ${ }^{6}$, Judit JEKISA ${ }^{1}$ and IstvÁn SZARUKÁN ${ }^{2}$ \\ 'Plant Protection Institute, HAS, Budapest, Hungary; e-mails: h2371tot@ella.hu, h2404sze@ella.hu \\ ${ }^{2}$ University of Debrecen, Faculty of Agricultural Sciences, Department of Plant Protection, Debrecen, Hungary; \\ e-mails: bozsik@helios.date.hu, asbolt@helios.date.hu \\ ${ }^{3}$ ENEA - C.R. Casaccia, Biotec-SIC, S. Maria di Galeria, Roma, Italy; e-mail: aletardi@casaccia.enea.it \\ ${ }^{4}$ Istituto Sperimentale per la Frutticoltura di Roma, Ciampino Aeroporto (RM), Italy; e-mail: tab55@mclink.it \\ ${ }^{5}$ Dipartimento di Protezione delle Piante, Sezione di Entomologia agraria Università degli Studi \& Sez. Ecologia applicata e \\ Controllo biologico I.S.E. [ex I.R.Co.B.A.] C.N.R, Sassari, Italy \\ ${ }^{6}$ Dipartimento Biologia applicata alla Difesa delle Piante Università degli Studi di Udine, Italy
}

Keywords. Neuroptera, Chrysopidae, Chrysoperla, green lacewings, attractant, phenylacetaldehyde

\begin{abstract}
At five sites in Hungary and Italy, traps baited with phenylacetaldehyde caught significantly higher numbers (10 to 100 times more) of green lacewings than unbaited traps, which demonstrates that this compound is an attractant. Traps with three bait dispensers usually caught more than those with one dispenser, but the difference was significant only at two out of five test sites. There was no difference in the numbers caught by sticky delta and funnel traps baited with phenylacetaldehyde. However, funnel traps could be adapted to catch living green lacewings. The vast majority of the specimens belonged to the Chrysoperla carnea species complex. Ch. carnea sensu lato dominated the catches at all sites. At some sites $3-11 \%$ of the insects caught were Ch. lucasina Lacroix. Phenylacetaldehyde-baited traps were attractive to both sexes, but generally more females were caught than males. Funnel traps baited with three dispensers of phenylacetaldehyde caught green lacewing adults throughout the season in Hungary.
\end{abstract}

\section{INTRODUCTION}

The common green lacewing Chrysoperla carnea s.l. is an important predator in the biological control of pest aphids, scales, caterpillars and other pests of many crops (McEwen et al., 2001). A synthetic attractant for green lacewings might be useful for monitoring lacewing abundance or manipulating lacewing population densities.

The attractants for green lacewings were reviewed by Szentkirályi (2001). The relatively few compounds that are attractants include methyl eugenol (Suda \& Cunningham, 1970; Umeya \& Hirao, 1975), methyl salicylate (Molleman et al., 1997; James, 2003), caryophyllene (Flint et al., 1979), 2-phenylethanol (Zhu et al., 1999) and some that are chemically undefined (McEwen et al., 1994; Harrison \& McEwen, 1998). In addition in a laboratory olfactometer bioassay, tethered female green lacewings spent ca $70 \%$ of the total time flying towards reaction mixtures thought to produce indole acetaldehyde (van Emden \& Hagen, 1976). This led van Emden \& Hagen (1976) to suggest that indole acetaldehyde is an attractant, however, they never tested the synthetized pure compound in the laboratory or the field.

In the course of field trapping in Hungary aimed at capturing female noctuids, common green lacewings (species of Chrysoperla carnea-complex, Neuroptera: Chrysopidae) were regularly caught by traps baited with phenylacetaldehyde (Tóth et al., unpubl.). This compound is a well known attractant for several Lepidoptera (e.g. Creighton et al., 1973; Cantelo \& Jacobson, 1979). The present research was undertaken to confirm this and to study the attractiveness of this compound to green lacewings. In the course of the experiments, the effectiveness of phenylacetaldehyde-baited traps (two dose levels) in capturing Chrysoperla spp. was compared with that of unbaited traps at several sites and in several habitats. This attractant, in combination with other attractants, or alone, may assist in the better management of green lacewings in Integrated Pest Management (IPM) strategies used in sustainable agriculture.

\section{MATERIAL AND METHODS}

\section{Trapping}

Tests were conducted routinely using the methods used in similar studies on pheromones and attractants (e.g. Arn et al., 1986; Roelofs \& Cardé, 1977). This was done at five sites in Hungary and Italy. Traps were suspended at a height of ca $1.5-1.7 \mathrm{~m}$. Green lacewings are frequently seen flying at these heights in the crown of trees. One replicate of each treatment was incorporated into a block so that individual treatments were 5-8 $\mathrm{m}$ apart (according to the distance between trees at the respective sites) and blocks were situated 15-20 m apart. Details of each experiment:

Halásztelek, Pest county, Hungary: the test was run in a cherry orchard from May 9 - June 10, 2003, with 6 replicated blocks. Traps were inspected twice weekly.

Lak, Borsod-Abaúj-Zemplén county, Hungary: the test was run in an apricot orchard from May 8 - September 19, 2003, with 5 replicated blocks. Traps were inspected twice weekly.

Ciampino (RM), Italy: the test was run in a peach orchard from May 14 - July 1, 2003, with 5 replicated blocks. Traps were inspected weekly.

Udine - S. Osvaldo (UD), Italy: two tests were run parallel, in an apple orchard and in a maize field, respectively, from May 22 - August 18, 2003, with 4 replicated blocks each. Traps were inspected weekly. 
TABLE 1. Catches of green lacewings (Chrysoperla spp.) in traps baited with one or three dispensers of phenylacetaldehyde and unbaited traps in 2003.

\begin{tabular}{|c|c|c|c|c|c|c|c|}
\hline & Test sites: & Halásztelek & Lak & Ciampino & Udine (apple) & Udine (maize) & Sassari (Sardegna) \\
\hline Trap type & $\begin{array}{l}\text { No. of bait } \\
\text { dispensers }\end{array}$ & $\begin{array}{l}\text { mean catch / } \\
\text { trap / inspection }\end{array}$ & $\begin{array}{l}\text { mean catch / } \\
\text { trap / inspection }\end{array}$ & $\begin{array}{l}\text { mean catch / } \\
\text { trap / inspection }\end{array}$ & total catch* & $\begin{array}{l}\text { mean catch / } \\
\text { trap / inspection }\end{array}$ & total catch* \\
\hline sticky & 1 dispenser & $0.91 b$ & N.T. & $1.07 \mathrm{~b}$ & 6 & $0.48 b$ & 11 \\
\hline sticky & 3 dispensers & $1.59 \mathrm{~b}$ & N.T. & $0.79 b$ & 7 & $0.92 \mathrm{c}$ & 16 \\
\hline sticky & no dispenser & $0.03 \mathrm{a} \#$ & N.T. & $0.10 \mathrm{a}$ & 0 & $0.00 \mathrm{a}$ & 1 \\
\hline funnel & 1 dispenser & $1.56 \mathrm{~b}$ & $2.88 \mathrm{~b}$ & N.T. & N.T. & N.T. & N.T. \\
\hline funnel & 3 dispensers & $1.97 \mathrm{~b}$ & $4.80 \mathrm{c}$ & N.T. & N.T. & N.T. & N.T. \\
\hline funnel & no dispenser & $0.00 \#$ & $0.06 \mathrm{a}$ & N.T. & N.T. & N.T. & N.T. \\
\hline \multicolumn{2}{|c|}{ Total number caught in test } & 211 & 1352 & 82 & 13 & 67 & 28 \\
\hline \multicolumn{2}{|c|}{$\%$ female } & 82.6 & 59.1 & 63.1 & 50.0 & 77.1 & N.A. \\
\hline \multicolumn{2}{|c|}{ Number of specimens sexed ${ }^{* *}$} & 207 & 1329 & 65 & 4 & 35 & 0 \\
\hline
\end{tabular}

Significance: means with same letter within one column not significantly different at $\mathrm{P}=5 \%$ by ANOVA, Games-Howell. Means with an "\#" not significntly different from a zero catch using Bonferroni-Dunn test $(\mathrm{P}=5 \%)$. * No statistics was performed due to the low numbers caught. $* *$ Only some of the insects caught were sexed. N.T. $=$ not tested in this particular experiment; N.A. $=$ not available.

Sassari - Serra Secca (SS), Italy: the test was run in an olive orchard from May 21 - August 13, 2003, with 4 replicated blocks. Traps were inspected weekly.

\section{Statistics}

The catches were transformed using $(\mathrm{x}+0.5)^{1 / 2}$ (Roelofs \& Cardé, 1977) and analysed by ANOVA. Treatment means were separated by Games-Howell Test (Games \& Howell, 1976; Jaccard et al., 1984). Where one of the treatments caught no insects it was omitted from the analysis. The Bonferroni-Dunn test (Dunn, 1961) was used to check that mean catches in other treatments were not significantly different from zero (see also Table and Figure legends). All statistical procedures were conducted using the software packages StatView ${ }^{\circledR}$ v4.01 and SuperANOVA ${ }^{\circledR}$ v1.11 (Abacus Concepts, Inc., Berkeley, USA).

\section{Trap types}

Sticky delta traps were the standard CSALOMON ${ }^{\circledR}$ RAG traps produced by the Plant Protection Institute, HAS (Budapest, Hungary), which are routinely used in Hungary for trapping many moth species. (Szöcs, 1993; Tóth \& Szöcs, 1993). Traps were made from transparent plastic sheets $(23 \times 36 \mathrm{~cm})$ by folding them into triangular prisms (length $23 \mathrm{~cm}$, all three sides $12 \mathrm{~cm}$; with the two ends open). Baits were suspended inside from the top in the center of each trap so that the bait was about 1-2 $\mathrm{cm}$ above the bottom sticky surface. Insects entering the traps were caught by replaceable sticky inserts $(16 \times 10 \mathrm{~cm})$, which were placed in the bottom of each trap.

Funnel traps were the standard CSALOMON® VARL+ funnel traps produced by the Plant Protection Institute, HAS (Budapest, Hungary), which were originally developed for capturing noctuids (Tóth et al., 2000), and proved to be suitable for some other moths (Subchev et al., 2003). This trap consists of an opaque plastic funnel (top opening outer diameter: $13 \mathrm{~cm}$, funnel hole diameter: $3 \mathrm{~cm}$, height of funnel: $16 \mathrm{~cm}$ ), with a 20 $\times 20 \mathrm{~cm}$ flat plastic roof and below a round transparent plastic container (ca 1 litre capacity; attached to the funnel by a rubber band). The bait was suspended from the middle of the roof and positioned slightly above the level of the upper edge of the large funnel opening. A small piece $(1 \times 1 \mathrm{~cm})$ of household antimoth strip (Chemotox ${ }^{\circledR}$, Sara Lee, Temana Intl. Ltd, Slough, UK; active ingredient $15 \%$ dichlorvos) placed in the container killed the captured insects.

\section{Baits}

Phenylacetaldehyde was obtained from Sigma-Aldrich Kft. (Budapest, Hungary) and was stated by the suppliers to be $>95 \%$ pure. For making the baits $100 \mathrm{mg}$ of phenylacetaldehyde was placed onto a $1 \mathrm{~cm}$ piece of dental roll (Celluron ${ }^{\circledR}$, Paul Hartmann Ag. Heidenheim, Germany), which was put into a polyethylene bag $(\mathrm{ca} 1.0 \times 1.5 \mathrm{~cm}$ ) made of $0.02 \mathrm{~mm}$ linear polyethylene foil. The dispensers were heat sealed and attached to $8 \times 1 \mathrm{~cm}$ plastic handles for easy handling when assembling the traps. Baits were wrapped singly in pieces of aluminum foil and stored at $-18^{\circ} \mathrm{C}$ until used. In the field baits were changed at 2-3 week intervals, which is the usual procedure when using phenylacetaldeyde baits for catching Lepidoptera.

\section{RESULTS}

Traps baited with one or three polyethylene bag bait dispensers loaded with phenylacetaldehyde caught higher numbers of green lacewings than unbaited traps (Table 1). The difference was significant at all sites where sufficient numbers were captured (at Halásztelek, Lak, Ciampino, Udine maize), which confirms that this compound is an attractant for green lacewings in the field (Table 1).

It was assumed that the release rate of the compound would be ca 3 times higher from traps with three dispensers than from those with only one dispenser, and this was used to provide a low and a high dose in each of the experiments. (Size of the traps made it impractical to use more than 3 dispensers in a trap.) Traps with three dispensers usually showed a tendency to catch more than those with one dispenser, but the difference was significant only at Lak and Udine (maize) (Table 1). This suggests that the release rate from a single dispenser was sufficient to attract green lacewings. It is possible that the release rate from three dispensers was close to optimum, so no dramatic increase in catches can be expected from further increasing the dose.

Both sticky delta and funnel traps baited with phenylacetaldehyde caught green lacewings and there was no difference in the catches of these two trap types (Table 1, Halásztelek). Funnel traps have the advantage that the insects from such traps were generally easier to identify than those from sticky traps. In the future, if a killing strip is not used, such funnel traps might prove suitable for catching live green lacewings. 

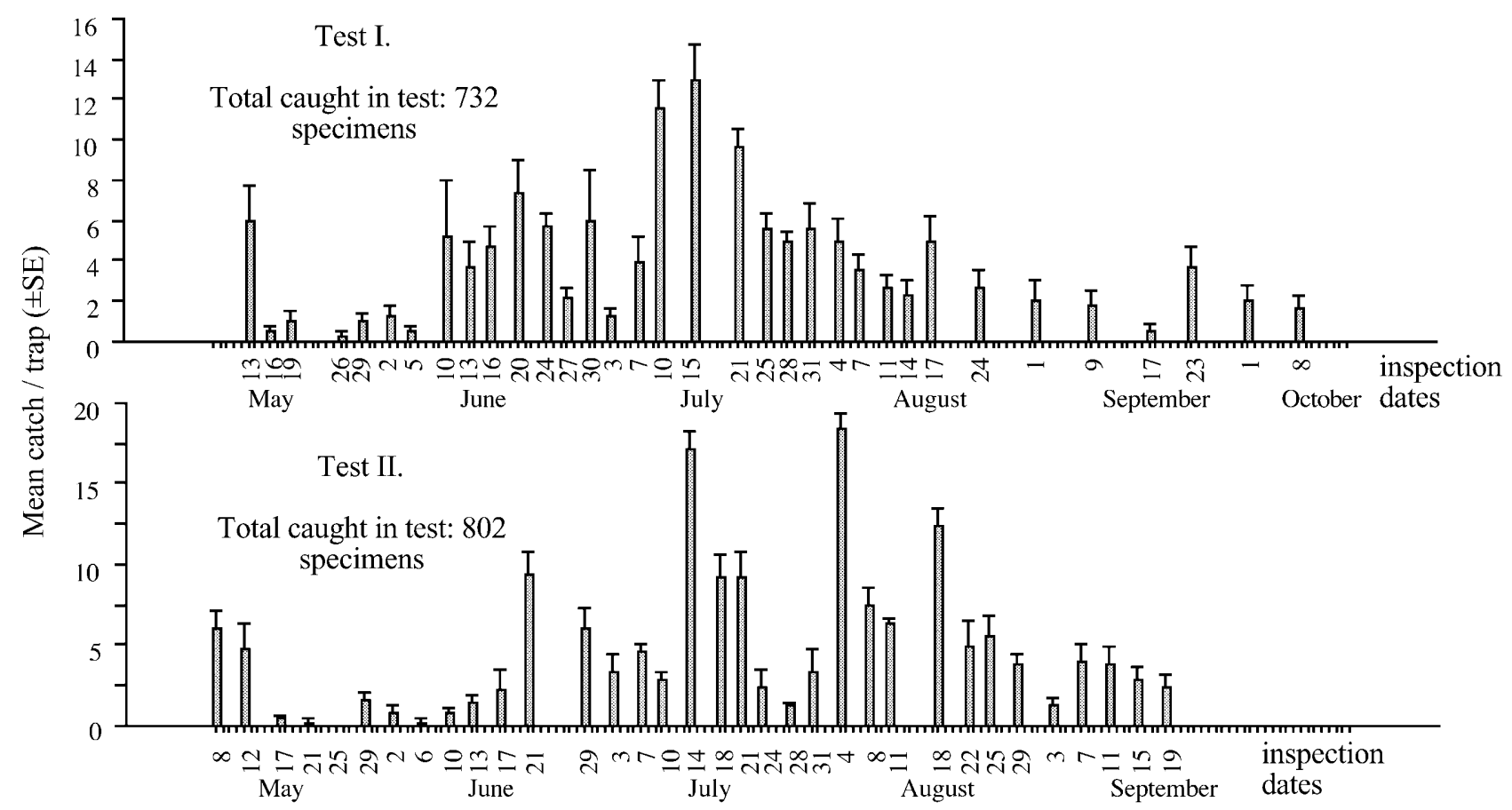

Fig 1. Mean catches of green lacewings in VARL + funnel traps baited with phenylacetaldehyde (3 dispensers) at two sites in Hungary in 2003. Test I: Halásztelek (Pest county), May 9 - October 10, 2003; Test II: Lak (Borsod-Abaúj-Zemplén county), May 6 - September 19, 2003.

The vast majority of the specimens caught in the traps belonged to the Ch. carnea species complex. Ch. carnea sensu lato dominated the catches at all sites, with $11.6 \%, 10.9 \%, 7.7 \%$ and $3.1 \%$ of Ch. lucasina Lacroix at the Halásztelek, Lak, Udine apple and Udine maize sites, respectively. At Ciampino and Sassari (Sardegna) all the specimens caught were Ch. carnea s.l.

Using the insects from Lak (where the largest numbers were captured) an attempt was made to attribute them to particular sibling species based on the descriptions (morphological characterization of adults) in the literature (Thierry et al., 1992, Duelli, 1996, Canard, pers. comm.) and by morphological comparison with voucher specimens of the various morphological types (courtesy of D. Thierry) and song morphs (courtesy of P. Duelli) (Henry et al., 2002) available in A. Bozsik's collection. Atypical and damaged specimens were excluded. According to these analyses the majority of specimens belonged to Ch. affinis Stephens (former Ch. kolthoffi Navás; Thierry et al., 1998). No such characterization of specimens from other sites was attempted.

Phenylacetaldehyde-baited traps caught both sexes of green lacewings, but generally more females than males (Table 1).

Funnel traps baited with three dispensers of phenylacetaldehyde caught green lacewing adults throughout the season in Hungary (Fig. 1)

\section{DISCUSSION}

Only a few substances are attractants for green lacewings (review by Szentkirályi, 2001). Methyl eugenol attracts Chrysopa spp. to traps (Suda \& Cunningham, 1970; Umeya \& Hirao, 1975). Methyl salicylate was found to attract green lacewings in a test originally aimed at pear psylla predators (Molleman et al., 1997), in particular Chrysopa nigricornis Burmeister (James, 2003). In another study, caryophyllene attracted green lacewings (Flint et al., 1979). Caryophyllene is a volatile generally produced by green leaves of most plants. In screening tests in Hungary (Tóth, unpubl.) neither methyl salicylate nor caryophyllene proved attractive [formulated in polyethylene bag dispensers; mean $( \pm \mathrm{SE})$ catches of $0.05 \pm 0.03$, $0.03 \pm 0.02$ and $0.03 \pm 0.02$ for caryophyllene, methyl salicylate, and unbaited traps, resp. $(\mathrm{F}=0.146, \mathrm{P}=0.864$ by ANOVA)]. With respect to caryophyllene, our unpublished results support those of Zhu et al. (1999), who found that Ch. carnea was not attracted to caryophyllene.

Tryptophane-based spray-baits have been used to increase common green lacewings (Chrysoperla carnea s.1.) in arable crops with variable results (McEwen et al., 1994; Harrison \& McEwen, 1998), which may in part be due to the confounding factors (i.e. any competing odours from the crop, influence of naturally-occurring prey populations, weather conditions that affect field results).

In an experiment originally aimed at capturing Helicoverpa armigera Hbn. (Lepidoptera: Noctuidae), Bruce et al. (2002) reported Ch. carnea in traps baited with the synthetic odour of African marigold (Tagetes erecta) and sweet pea (Lathyrus odoratus) flowers. Both of these odours contained a significant amount of phenylacetaldehyde (ca $2.3 \%$ for $T$. erecta and ca $31 \%$ for L. odoratus, respectively, in addition to other compounds), so probably the presence of this compound was responsible, at least in part, for the attractiveness of these odours for lacewings.

2-Phenylethanol, a compound structurally related to phenylacetaldehyde, is reported to attract significant numbers of $C h$. carnea (Zhu et al., 1999).

Phenylacetaldehyde is a common constituent of flower scents (Knudsen et al., 1993). Green lacewing adults are frequently observed visiting flowers, feeding on pollen and nectar (Bozsik, 2000; Canard, 2001), therefore their response to the floral scent constitutent phenylacetaldehyde, demonstrated in this study, may be a part of the chemical communication used to locate a feeding site. 


\section{CONCLUSIONS}

Chrysoperla carnea s.l. is an important biological control agent of several pest insects. The attractant discovered in this study is attractive to both females and males. The insects caught consisted in most cases of somewhat more females of the common green lacewing, whereas a wide range of plant volatiles tested by Dodds \& McEwen (1998) using electroantennograms showed a stronger response by males of Ch. carnea. Further research will focus on the possibility of using the new attractant on its own or in combination with other attractants for studying lacewings in different crops.

ACKNOWLEDGEMENTS. The present study was partially supported by grant NKFP-4/012/04 OM from the Hungarian Ministry of Education. Study trips of R. T. and T. M. were generously supported by the Bilateral Intergovernmental S\&T Cooperation I-17/99 between Italy and Hungary.

\section{REFERENCES}

Arn H., Rauscher S., Buser H.R. \& Guerin P.M. 1986: Sex pheromone of Eupoecilia ambiguella female: analysis and male response to ternary blend. J. Chem. Ecol. 12: 1417-1429.

BozsiK A. 2000: Nahrungsanalytische Untersuchungen an einigen mitteleuropäischen Chrysopiden-Imagines (Neuroptera: Chrysopidae). Beitr. Entomol. 50: 237-246.

Bruce T.J., Cork A., Hall D.R. \& Dunkelblum E. 2002: Laboratory and field evaluation of floral odours from African marigold, Tagetes erecta, and sweet pea, Lathyrus odoratus, as kairomones for the cotton bollworm Helicoverpa armigera. IOBC WPRS Bull. 25: 315-322.

CANARD M. 2001: Natural food and feeding habits of lacewings. In McEwen P.K., New T.R. \& Whittington A.E. (eds): Lacewings in the Crop Environment. Cambridge University Press, Cambridge, pp. 116-129.

Cantelo W.W. \& Jacobson M. 1979: Phenylacetaldehyde attracts moths to bladder flower and blacklight traps. Environ. Entomol. 8: 444-447.

Creighton C.S., McFadden T.L. \& Cuthbert E.R. 1973: Supplementary data on phenylacetaldehyde: an attractant for Lepidoptera. J. Econ. Entomol. 66: 114-115.

DodDs C. \& McEwen P.K. 1998: Electroantennogram responses of green lacewings (Chrysoperla carnea) to plant volatiles: preliminary results. In Panelius S.P. (ed.): Neuropterology 1997. Proceedings of the Sixth International Symposium on Neuropterology. Helsinki, Finland, 13-16 July 1997. Acta Zool. Fenn. 209: 99-102.

Duelli P., Henry C.S. \& Johnson J.B. 1996: Herausforderung für die Systematik, die angewandte Entomologie und den Naturschutz. In Gerstmeier R (ed.): Verhandlungen 14 International Symposium über Entomofaunistik in Mitteleuropa, SIEEC, München, pp. 383-387.

DunN O.J. 1961: Multiple comparisons among means. J. Am. Stat. Assoc. 56: 52-64.

Flint H.M., SAlter S.S. \& Walters S. 1979: Caryophyllene: an attractant for the green lacewing. Environ. Entomol. 8: $1123-1125$.

Games P.A. \& Howell J.F. 1976: Pairwise multiple comparison procedures with unequal n's and/or variances: a Monte Carlo study. J. Educ. Stat. 1: 113-125.

Harrison S.J. \& McEwen P.K. 1998: Acid hydrolysed L-tryptophan and its role in the attraction of the green lacewing Chrysoperla carnea (Stephens) (Neuropt., Chrysopidae). Z. Angew. Entomol. 122: 343-344.
Henry C.S., Brooks S.J., Duelli P. \& Johnson J.B. 2002: Discovering the true Chrysoperla carnea (Insecta: Neuroptera: Chrysopidae) using song analysis, morphology, and ecology. Ann. Entomol. Soc. Am. 95: 172-191.

JACCARD J., Becker M.A. \& Wood G. 1984: Pairwise multiple comparison procedures: a review. Psychol. Bull. 96: 589-596.

JAMES D.G. 2003: Field evaluation of herbivore-induced plant volatiles as attractants for beneficial insects: methyl salicylate and the green lacewing, Chrysopa nigricornis. J. Chem. Ecol. 29: $1601-1609$.

Knudsen J.T., Tollsten L. \& Bergström L.G. 1993: Floral scents - a checklist of volatile compounds isolated by headspace techniques. Phytochemistry 33: 253-280.

McEwen P.K., Jervis M.A. \& KIDD N.A.C. 1994: Use of sprayed L-tryptophan solution to concentrate numbers of the green lacewing Chrysoperla carnea in olive tree canopy. Entomol. Exp. Appl. 70: 97-99.

McEwen P.K., New T.R. \& Whittington A. (eds) 2001: Lacewings in the Crop Environments. Cambridge University Press, Cambridge, 546 pp.

Molleman F., Drukker B. \& Blommers L. 1997: A trap for monitoring pear psylla predators using dispensers with the synomone methylsalicylate. Proc. Exp. Appl. Entomol. (N.E.V. Amsterdam) 8: 177-182.

RoELOFS W.L. \& CARDÉ R.T. 1977: Responses of Lepidoptera to synthetic sex pheromone chemicals and their analogues. Annu. Rev. Entomol. 22: 377-405.

Subchev M., Toshova T., Tóth M., Voigt E., Mikulás J. \& Francke W. 2003: Catches of vine bud moth Theresimima ampellophaga (Lep., Zygaenidae: Procridinae) males in pheromone traps: effect of the purity and age of baits, design, colour and height of the traps, and daily sexual activity of males. Z. Angew. Entomol. 127: 1-7.

Suda D.Y. \& Cunningham R.T. 1970: Chrysopa basalis captured in plastic traps containing methyl eugenol. J. Econ. Entomol. 63: 1706.

SzENTKIRÁLYI F. 2001: Chemical ecology of lacewings. In McEwen P.K., New T.R. \& Whittington A.E. (eds): Lacewings in the Crop Environment. Cambridge University Press, Cambridge, pp. 100-115.

Szöcs G. 1993: [Pheromone traps on the Hungarian market.] Növényvédelem 29: 191-193 [in Hungarian].

Thierry D., Cloupeau R. \& Jarry M. 1992: La chrysope commune Chrysoperla carnea sensu lato dans le centre de la France: mise en évidence d'un complexe d'espèces (Insecta: Neuroptera: Chrysopidae). In Canard M., Aspöck H. \& Mansell M.W. (eds): Current Research in Neuropterology. Proceedings of the 4th International Symposium on Neuropterology. Bagneres-de-Louchon, France, 1991. SACCO, Toulouse, pp. 379-392.

Thierry D., Cloupeau R., Jarry M. \& Canard M. 1998: Discrimination of the West-Palearctic Chrysoperla Steinmann species of the carnea Stephens group by means of claw morphology (Neuroptera, Chrysopidae). Acta Zool. Fenn. 209: 255-262.

Tóth M. \& SzÖCS G. 1993: [Pheromone studies of one and a half decade at the Plant Protection Isntitute.] Növényvédelem 29: 101-109 [in Hungarian].

Tóth M., Imrei Z. \& Szöcs G. 2000: [Non-sticky, non-saturable, high capacity new pheromone traps for Diabrotica virgifera virgifera (Coleoptera: Chrysomelidae) and Helicoverpa (Heliothis) armigera (Lepidoptera: Noctuidae).] In Ripka G., Vendrei Zs., Olasz Zs., Spilák K., Kovács G. (eds): Integrált termesztés a kertészeti és szántóföldi kultúrákban. [Integral Control in Horticultural and Field Crops.] BFNTÁ, Budapest, pp. 44-49 [in Hungarian]. 
Umeya K. \& Hirao J. 1975: Attraction of the Jackfruit fly, Dacus umbrosus F. (Diptera: Tephritidae) and lacewing, Chrysopa sp. (Neuroptera: Chrysopidae) by lure traps baited with methyl eugenol and cue-lure in the Philippines. Appl. Entomol. Zool. 10: 60-62.

van EMdEN H.F. \& HAGEN K.S. 1976: Olfactory reactions of the green lacewing, Chrysopa carnea, to tryptophan and certain breakdown products. Environ. Entomol. 5: 469-473.
Zhu J.W., Cosse A.A., Obrycki J.J., Boo K.S. \& BaKer T.C. 1999: Olfactory reactions of the 12-spotted lady beetle, Coleomegilla maculata and the green lacewing, Chrysoperla carnea to semiochemicals released from their prey and hostplant - electroantennogram and behavioral-responses. $J$. Chem. Ecol. 25: 1163-1177.

Received March 2, 2005; revised and accepted July 7, 2005 